\title{
TESTING WeAK FoRm EFFICIENCY IN THE SOUTH AFRICAN MARKET
}

\author{
Elmar Gräter* \\ University of Johannesburg \\ EGrater@fnb.co.za
}

Received: September 2014

\author{
Jean Struweg\# \\ University of Johannesburg \\ jstruweg@uj.ac.za
}

Accepted: January 2015

\begin{abstract}
This paper furthers the work on efficiency of developing markets with specific focus on the JSE Limited. Empirical work on the efficiency of the JSE has been mixed; evidence both in favour of and against weak form efficiency is prominent. If markets are efficient new information immediately influences market prices; accordingly, prices follow a random walk and investors will not be able to continuously earn abnormal returns. Both the Augmented Dickey-Fuller and Phillips-Perron tests were employed to test whether the JSE followed a random walk between 1999 and 2014. The null hypothesis $\left(H_{0}\right)$ for both tests is that the series of logarithmic returns has a unit root and is therefore weak form efficient. In both tests this $\mathrm{H}_{0}$ is rejected, which proves that for the period under analysis the JSE was not weak form efficient. The influence of factors such as market size and liquidity on efficiency is also discussed.
\end{abstract}

\section{Keywords}

Market Efficiency, Random Walk, Unit Root, Augmented Dickey-Fuller, Phillips-Perron, Stock Market, Emerging Market, $\varepsilon M H$

*Mr $\varepsilon$ Gräter is a master's students in the Department of Finance and Investment Management, University of Johannesburg, South Africa.

\#Mr J Struweg is a senior lecturer in the Department of Finance and Investment Management, University of Johannesburg, South Africa. 


\section{INTRODUCTION}

Recent financial development has seen securities from emerging economies, including those listed on the JSE Limited (JSE), take a prominent role in the portfolios of international investors. Although the South African economy falls under the category of developing economy its stock market more closely resembles that of a developed country since the JSE is substantially ahead of the stock markets of other African countries with regard to both size and sophistication (Smith, Jefferis \& Ryoo, 2002).

The benefits of stock markets to an economy are diverse and include, inter alia, the attraction of foreign portfolio investment, increased domestic savings as well as bolstering the availability of capital for domestic investments. Overall, stock markets are believed to improve the general functioning of the local financial system and the capital market in particular. Smith et al. (2002) further state that the positive impact of stock markets on the operation of capital markets is dependent on two factors, firstly the allocation and pricing of capital and secondly the pricing of risk.

The efficiency of a stock market can be tested through the use of the random walk hypothesis and it can be applied to either individual shares or general indices. The origin of the concept is not credited to a specific scholar, although authors such as Fama (1965) and Malkiel (1973) contributed much to its prominence in economics and investments. The random walk hypothesis asserts that market prices move in a random manner, and as such price movements cannot be predicted. This is consistent with the efficient market hypothesis (EMH). If a random walk is not present then there may be distortion in the pricing of capital and risk, meaning market prices could be out of equilibrium. This has drastic implications for the allocation of capital within an economy (Smith et al., 2002).

Along with the increased consideration of emerging markets as an investment option, research into the efficiency of these markets has also proliferated. There have been numerous empirical studies regarding the efficiency of African stock markets, especially regarding the JSE due to it being the biggest on the African continent (Jefferis \& Smith, 2005; Morris, van Vuuren \& Styger, 2009; Almudhaf \& Alkulaib, 2013; Smith et al., 2002).

Mollah (2007) explains that the increased consideration of emerging markets for inclusion in international portfolios could be one of the main reasons for an increasing recognition of research on emerging markets, especially around the efficiencies of these markets and their functioning. Although markets such as those of Latin America and Asia are considered more prominent, the development and growth on the African continent has seen the establishment of numerous exchanges in recent times.

Empirical research regarding the efficiency of the JSE is not conclusive, with some studies finding it efficient while others concluding that it is inefficient. The aim of this paper is to provide insight into the efficiency of the JSE between 1999 and 2014 through the use of the Augmented Dickey-Fuller (ADF) test and Phillips-Perron (PP) test. In addition to this the paper also discusses the $\varepsilon M H$, as well as the random walk model, which is often utilised as a method for testing the efficiency of markets. An insight into these topics will add to the understanding of market efficiency of the JSE. 


\section{SOUTH AFRICA AND OTHER DEVELOPING MARKETS}

Smith et al. (2002) writes that financial developments over the last two decades have led to emerging markets being increasingly considered for the portfolios of international investors.

Nurunnabi (2012) supplements this by stating that in recent times the efficiency of markets in developing countries has increased drastically. This can largely be attributed to globalisation and the increased free movement of capital between countries, which has directly led to an influx of capital into developing countries. Historically, emerging markets have been considered drastically inefficient in comparison to developed markets (Youssef \& Galloppo, 2013), and this is partly due to underdevelopment in these countries, which resulted in lower levels of regulation and control.

The JSE was first established largely for the purpose of raising finance for emerging gold mining ventures (Smith et al., 2002) and is still dominated by resource shares (Colombo, 2014). Liquidity concerns on the JSE are compounded by the domination of share ownership by large conglomerates associated with mining companies and financial holding companies. A reason for these large holdings is the strict exchange controls set by the South African government on capital repatriation prior to 1994, which restricted South African firms from exporting capital. This left them with little to do with locally earned profits but to invest them locally (Smith et al., 2002).

Almudhaf and Alkulaib (2013) describe the South African market as being well diversified, however: they observe that it is rich in resources such as gold and platinum, and that it also proved robust enough to recover after the global economic downturn which following the US subprime crisis of 2007. A concern with African markets in general is their overall lack of liquidity. When turnover is used as a global ranking measure as opposed to market capitalisation African markets' positions in global rankings is greatly diminished, and this is true also for the JSE.

\section{EFFICIENT MARKET HYPOTHESIS AND ITS IMPORTANCE}

Fama (1965), the originator of the $\varepsilon M H$, stated that efficient markets consist of many rational investors who compete directly with each other to predict future prices in a market where information is freely available. The result is that competition will lead to new information immediately being absorbed and reflected in current market prices. A market in which prices always fully reflect all available information is considered efficient. If the EMH holds it has implications for investors that claim to systematically outperform the market. Almudhaf and Alkulaib (2013) add that since Fama (1965) introduced the concept of market efficiency it remains a significant consideration with regard to resource (capital) allocation and portfolio investment. It is worth noting that the EMH was conceptualised more than 50 years ago, and is still considered a significant theory in the realm of finance and investments, even if only for the lack of plausible alternatives.

Nurunnabi (2012) provides a summary of the three forms of market efficiency, namely weak form, semi-strong and strong form. Weak form efficiency is the market state where current market prices reflect all historical information, which may affect the price. Semi-strong form efficiency is observed when current market prices reflect not only all historical information, but all publicly available information. In the case of strong form efficiency, market prices reflect all information whether public or private. 
The level of efficiency of a stock market is important, since efficiency will determine the extent to which the benefits of such a market, such as efficient capital allocation and risk pricing, will materialise (Smith et al., 2002). The less efficient a market is, the less of these benefits will result and vice versa. If stock markets are to improve the operation of capital markets then the allocation and pricing of capital and the pricing of risk are vital. Therefore analyses of stock markets tend to focus on the price formation process or determinants of stock returns (Smith et al., 2002). Youssef and Galloppo (2013) go on to explain that the efficiency of capital markets also plays a critical role in the evaluation of firms in the market and the required rate of return used to evaluate them. This discount rate or required rate of return is a function of the market risk premium and a risk free rate. If markets are efficient and prices fully reflect future firm performance, then discount rates applied are considered appropriate, and a premise for efficient capital allocation is set. On the other hand if stock market prices are determined inefficiently it could have social cost implications such as firms acquiring capital more cheaply, or more expensively, than they are supposed to, which will lead to inappropriate gains or losses.

In an efficient market where information becomes available randomly, and is absorbed into prices, it follows that prices will change randomly. Testing for the presence of a random walk in prices is one way of determining the level of market efficiency.

In efficient markets the random walk hypothesis states that current market prices reflect the markets' best estimates of risk and expected return for each individual security. Where markets are not efficient prices do not speedily adjust to new information. This allows investors in possession of private information to benefit by trading according to the anticipated direction of price movement (Youssef \& Galloppo, 2013).

Random walk tests can be applied to an individual stock, portfolio of stocks or market index. If the random walk model holds it means that markets are efficient and investors should be unable to consistently earn abnormal returns. On the other hand if the random walk model does not hold it provides evidence that there are distortions present in the pricing of risk and capital (Smith et al., 2002), which may be indicative of a lower level of efficiency.

\section{EVIDENCE IN LITERATURE REGARDING MARKET EFFICIENCY}

Shiller (2003) states that academic finance has come a long way since the time when the efficiency of markets was considered to have been proven. There have been many empirical studies investigating whether the EMH holds, and these studies have yielded mixed results. Work in support of the EMH came from Fama (1970), Sorensen (1982) and Pearce and Roley (1983). Subsequent research from Shiller (1979) and Rosenberg et al. (1985) found several anomalies. The contradictory findings showed that volatility was too severe to support the EMH theory. Varamini and Kalash (2008) added that the EMH is not favoured by investors, whose objective is to earn superior returns. This is not surprising, since efficiency implies earning superior returns is not possible.

A closer examination of the efficiency of the JSE yields mixed findings. Smith et al. (2002) considered the efficiency of a number of African countries' markets including the JSE. Through the use of the multiple variance ratio tests they found that the JSE is efficient and that the null hypothesis of a random walk is not rejected. 
This is supplemented by the work of Almudhaf and Alkulaib (2013), which uses the Augmented Dickey-Fuller (ADF) and Phillips-Perron (PP) tests and variance ratio tests to examine the efficiency of the JSE. They conclude that the JSE follows a random walk process.

In addition, Jefferis and Smith (2005) use the GARCH model with time varying parameters to establish a test of evolving efficiency (TEE). The test period ranges from the early 1990 s until June 2001, with the aim of detecting changing in efficiency over time. Of the seven African markets (South Africa, Egypt, Morocco, Nigeria, Zimbabwe, Mauritius and Kenya) considered they found that the South African market (JSE) was the only one to be weak form efficient through the entire period under consideration. Three markets - Egypt and Morocco from 1999 and then Nigeria from 2001 - become weak form efficient towards the end of the sample period.

Contrasting results are reported by Morris, van Vuuren and Styger (2009), who through the use of a Wavelet analysis found that individual share prices of the JSE as well as general indices tend to be mean reverting over a long time period, indicating that they exemplify a long memory process, evidence that the market is not weak form efficient.

This is supplemented by Appiah-Kusi and Menyah (2003), who studied the performance of 11 African markets including the JSE; they tested for weak form efficiency through the use of logistics map and EGARCH-M modelling, and found that the JSE was weak form inefficient.

In addition, Lim (2009) studied the nonlinear serial dependence of South Africa and four other Middle Eastern and African countries and concluded that after removing all short-term linear dependence in the time series nonlinearity tests still contained predictable nonlinearities, thereby contradicting the required criteria for the weak-form EMH.

Therefore the empirical findings around the efficiency of the JSE are not conclusive. From the studies outlined above it is clear that deciding whether or not the market is efficient could possibly be influenced by factors such as the test being utilised, period of analysis and also the frequency of the data points, i.e. whether monthly or daily returns.

\section{DATA SET AND METHODOLOGY}

The random walk model states that price changes cannot be predicted through the utilisation of historical price changes, that price changes are independent of each other and that price changes occur without any significant or visible trends (Nurunnabi, 2012).

The random walk formula is as follows (Nurunnabi, 2012):

$$
\begin{gathered}
P_{t+1}=n+P_{t}+\varepsilon_{t+1} \\
P_{t+1}=\text { Price of Share at Time } t+1 \\
n=\text { Expect Price Change } \\
P_{t}=\text { Price of Share at Time } t \\
\varepsilon_{t+1}=\text { Random Error Term with Zero Mean and Finite Variance }
\end{gathered}
$$

Ko and Lee (1991) state that if the random walk model holds then the weak form EMH must also hold. Fama (1970) supported the use of the random walk model to test for weak form market efficiency and accordingly a significant portion of the historical empirical research utilises the random walk model to test for it. This empirical research includes the work of Groenewald and 
Kang (1993) in testing the efficiency of Australian stock markets, Huang (1995) for Asian markets and that of Smith et al. (2002) for African markets.

The analysis will be performed on the JSE's All Share Index (ALSI) using returns on a monthly basis. This is consistent with Aga and Berna (2008), who tested for market efficiency in the Istanbul Stock Exchange, and used a monthly index. It is also argued that monthly closing prices eliminate some of the intra-day volatility that the use of daily prices gives rise to. Smith et al. (2002) suggest that the use of a broad-based index will lead to the test's results being more representative of the entire market.

This data is sourced from Bloomberg, with monthly returns being calculated by taking the logarithmic difference with the formula below (Aga \& Berna, 2008):

$$
\begin{gathered}
r_{i t}=\operatorname{Ln}\left(P_{i t}\right)-\operatorname{Ln}\left(P_{i, t-1}\right) \\
r_{i t}=\text { Return of Index } i \text { for Month } t \\
P_{i t}=\text { Monthly Closing Price of the Index for Period } t \\
P_{i, t-1}=\text { Monthly Closing Price of the Index for Period } t-1
\end{gathered}
$$

The sample for this study ranges from October 1998 up until April 2014. This period incorporates both the effects of the dotcom bubble, which reached its peak in the early parts of 2000 , as well as the subprime mortgage and eurodebt crisis that was experienced from 2007 onwards. It also covers periods in which the JSE experienced both bull and bear markets.

According to Kapusuzoglu (2013) when a series has a unit root the time series can be branded as having the characteristics of a random walk. These series do not return to their average values over time after a shock has occurred; accordingly, they follow a random course. The random walk hypothesis therefore argues that such changes observed in the time series over time are random in nature. If this random walk is present in the South African ALSI the market can be considered at least weak form efficient.

Kapusuzoglu (2013) inspects the weak form efficiency of the Istanbul Stock Exchange; a similar methodology will be applied to determine if the JSE is weak form efficient, through the use of ADF and PP tests. Brooks (2008) states that the basic objective of both the ADF and PP tests is to examine the null hypothesis $\left(H_{0}\right)$ that $\varnothing=1$ in the formula below. This is tested against the onesided alternative hypothesis $\left(H_{a}\right)$ that $\emptyset<1$.

$$
y_{t}=\emptyset y_{t-1}+u_{t}
$$

It follows that for ADF and PP the hypotheses of interest are:

$\mathrm{H}_{0}$ : that the series does have a unit root, versus

$H_{a}$ : that the series is stationary and accordingly does not have a unit root (Brooks, 2008).

Brooks (2008) writes that Phillips and Perron developed what can be described as a more comprehensive theory of unit root non-stationarity. Almudhaf and Alkulaib (2013) add that the main difference between the ADF and PP tests is that the PP test incorporates an automated correction to the ADF process allowing for the auto-correlated residuals. Yet according to Brooks (2008), both tests often come to the same conclusion.

Kapusuzoglu (2013) proceeds to explain that the decision to reject or fail to reject the $\mathrm{H}_{0}$ is based on the t-statistics, which is obtained from each of the tests outlined above. If the absolute value of the $t$-statistic is greater than the critical value then the $\mathrm{H}_{0}$ will be rejected and 
it will mean that the series is stationary and doesn't have a unit root. The calculated t-statistics are compared to the critical value at a $1 \%, 5 \%$ and $10 \%$ significance level.

\section{RESULTS AND DISCUSSION}

FIGURE 1 reports the descriptive statistics of monthly returns of the JSE between 1999 and 2014. The histogram of returns at a first glance resembles a somewhat negatively skewed distribution; this is confirmed when the negative skewness of 0.28 is considered and the series is also leptokurtic with a kurtosis reading above three. Utilising the Jarque-Bera test it is possible to reach a conclusion regarding the distribution of the returns. The null hypothesis $\left(\mathrm{H}_{0}\right)$ that the returns are normally distributed is not rejected due to the probability value ( $p$-value) being greater than the significance level of 0.05 ; accordingly the series is normally distributed. Although the skewness and kurtosis readings from the descriptive statistic do not indicate a perfectly normal distribution it is important to note that those measures in this case are skewed by a few outliers, although not many because the skewness and kurtosis reported are insignificant.

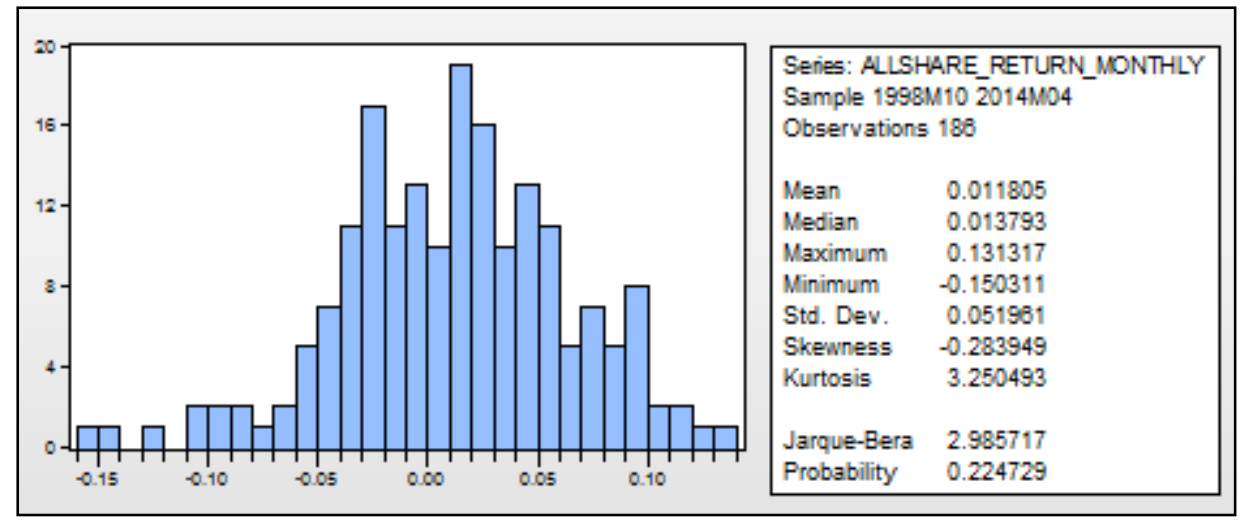

\section{FIGURE 1: Descriptive Statistics of JSE Returns}

Source: Eviews

While the normal distribution of returns is usually an indicator of efficient markets, it is vital to take into consideration that the Jarque-Bera test and descriptive statistics are utilised only as an intuitive measure of the returns. The ADF and PP tests are significantly more formal and reliable tests for the weak form efficiency of a market when compared to the Jarque-Bera test (Asteriou \& Hall, 2011).

The results for the ADF and PP test applied to the JSE ALSI monthly returns for the period between October 1998 up until April 2014 both on the level and first differences are presented in Figures 2 through 5 below. 


\begin{tabular}{|c|c|c|c|}
\hline \multicolumn{4}{|c|}{$\begin{array}{l}\text { Null Hypothesis: ALLSHARE_RETURN_MONTHLY has a unit root } \\
\text { Exogenous: Constant } \\
\text { Lag Length: } 0 \text { (Automatic - based on SIC, maxlag=14) }\end{array}$} \\
\hline & & t-Statistic & Prob. * \\
\hline \multicolumn{2}{|c|}{ Augmented Dickey-Fuller test statistic } & -14.00473 & 0.0000 \\
\hline Test critical values: & $\begin{array}{c}1 \% \text { level } \\
5 \% \text { level } \\
10 \% \text { level }\end{array}$ & $\begin{array}{l}-3.465780 \\
-2.877012 \\
-2575097\end{array}$ & \\
\hline
\end{tabular}

\section{FIGURE 2: Augmented Dickey-Fuller (ADF) Test - Level}

Source: Eviews

\begin{tabular}{|c|c|c|c|}
\hline \multicolumn{4}{|c|}{$\begin{array}{l}\text { Null Hypothesis: D(ALLSHARE_RETURN_MONTHLY) has a unit root } \\
\text { Exogenous: Constant } \\
\text { Lag Length: } 2 \text { (Automatic- based on SIC, maxlag=14) }\end{array}$} \\
\hline & & t-Statistic & Prob.* \\
\hline \multicolumn{2}{|c|}{ Augmented Dickey-Fuller test statistic } & -13.22441 & 0.0000 \\
\hline \multirow{3}{*}{ Test critical values: } & $1 \%$ level & -3.466377 & \\
\hline & $5 \%$ level & -2.877274 & \\
\hline & $10 \%$ level & -2.575236 & \\
\hline
\end{tabular}

\section{FIGURE 3: Augmented Dickey-Fuller (ADF) Test - First Difference}

Source: Eviews

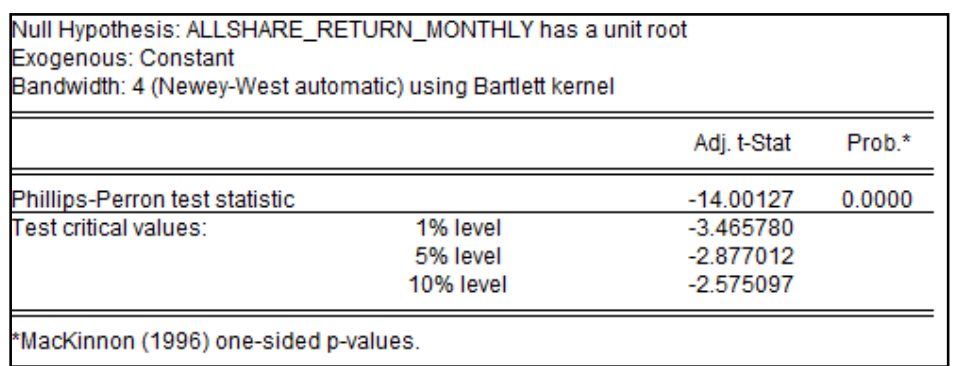

\section{FIGURE 4: Phillips-Perron (PP) Test - Level}

Source: Eviews 


\begin{tabular}{|c|c|c|c|}
\hline \multicolumn{4}{|c|}{$\begin{array}{l}\text { Null Hypothesis: D(ALLSHARE_RETURN_MONTHLY) has a unit root } \\
\text { Exogenous: Constant } \\
\text { Bandwidth: } 33 \text { (Newey-West automatic) using Bartlett kernel }\end{array}$} \\
\hline & & Adj. t-Stat & Prob. * \\
\hline \multicolumn{2}{|c|}{ Phillips-Perron test statistic } & -81.23882 & 0.0001 \\
\hline \multirow{3}{*}{ Test critical values: } & $1 \%$ level & -3.465977 & \\
\hline & $5 \%$ level & -2.877099 & \\
\hline & $10 \%$ level & -2.575143 & \\
\hline
\end{tabular}

\section{FIGURE 5: Phillips-Perron (PP) Test - First Difference}

Source: Eviews

As discussed earlier, the $\mathrm{H}_{0}$ for both the ADF and PP tests is that the series has a unit root and therefore follows a random walk, which is consistent with at least weak form efficiency. As can be seen in Figures 2 through 5, the ADF and PP tests have an absolute t-statistic value greater than the critical value of two at the $1 \%, 5 \%$ and $10 \%$ significance level for both the level and first difference tests; the same conclusion can be reached by comparing the probability value ( $p$-value) to the significance level. Due to the $p$-value of 0.00 being less than $1 \%$ for all tests on both the level and first difference the $\mathrm{H}_{0}$ can be rejected across all tests on both the level and first difference. This leads to the conclusion that the logarithmic returns of the JSE for the period of analysis are stationary at the level and first difference. As a result of not having a unit root it can be said that when a shock had occurred it did not lead to the series drawing away from its average value in future periods; due to not deviating significantly from its average value the prediction of future prices is possible (Kapusuzoglu, 2013). Therefore the markets are considered to be weak form inefficient.

\section{CONCLUSION}

Smith et al. $(2002,482)$ allude to two reasons why some markets may not be efficient. They discuss factors that could influence the efficiency of a market, and ask what could drive a market from being inefficient to being efficient. The first factor to consider is the sheer size of the market: they explain that there could be a size requirement before markets can start being classified at efficient. The second consideration, and one which is an important consideration in the African context, is the liquidity of a market. They state that in a market where the levels of turnover are not significant relative to its size it becomes difficult to envision such a market having sufficient trading which would lead to the market following a random walk and being efficient. An example of this is that if there is very low turnover on a market it may result in some stocks not getting traded at all from one period to the next, and due to there being no trading the price of the stock cannot change (Smith et al., 2002).

The argument of Smith et al. (2002) surrounding the effect of liquidity on efficiency is supported by a number of other studies, such as the research of Smith and Ryoo (1998), where it was found that the market in Turkey, which is relatively small but the most liquid of the European emerging markets, was efficient. Also Urrutia (1995) found that out of all the Latin American stock markets only the Argentinean market was efficient; the Argentinean market also happens to be the most liquid of the Latin American markets. Combining the work of Smith et al. (2002) with 
the other empirical research it becomes evident that liquidity could be a contributing reason to the lack of efficiency in the price formation of the JSE.

The literature showed that if markets are efficient then market prices should immediately reflect all new information; accordingly no investor will be able to continuously outperform the market, and earn excess returns. Weak form efficiency implies that current share prices reflect all historical information, and, as such, where weak form efficiency is present, investors will not be able to continuously earn excess returns.

Two different tests, namely the Augmented Dickey-Fuller test and the Phillips-Perron test, were used to establish whether the logarithmic returns of the index had a unit root. If the series does have a unit root it would mean that price movements were random and accordingly markets were weak form efficient. Both tests yielded the same result, rejecting the $\mathrm{H}_{0}$ that markets have a unit root at both the level and first difference of the series. This implies that the series is stationary and therefore there is a level of predictability in future returns of the market meaning markets are not weak form efficient.

The results of these tests and conclusions regarding the inefficiency of the JSE support the findings of Morris et al. (2009), Appiah-Kusi and Menyah (2003) and Lim (2009), who also found the JSE to not be weak form efficient. Nisar and Hanif (2012) argue that due to the importance of market efficiency it is vital for regulators to intervene and implement steps that lead to more efficient markets. Possible improvements to the financial system include the optimised linkages between the entire financial system, more wide and free distribution of information, the equal distribution of information and a decrease in transaction costs.

The findings from this research indicate that the JSE ALSI was not weak form efficient between 1999 and 2014. While further research needs to be done regarding the reason and characteristics which cause it to be inefficient, it is important to keep in mind the argument of Shiller (2003), which states that while the $E M H$ is a valuable theoretical model it should not be used as a representation of the activities happening in actual markets.

Future research relating to the efficiency of the JSE could also consider the various factors which could influence the efficiency of developing markets, such as the size and liquidity of the market, market regulation, costs associated with transacting, institutional characteristics of the market and lastly the characteristics of the market's investors.

\section{LIST OF REFERENCES}

Aga, M. \& Kocaman, B. (2008). Efficient market hypothesis and emerging capital markets: empirical evidence from Istanbul Stock Exchange. International Research Journal of Finance and Economics, 13(1), pp. 131-144.

Almudhaf, F. \& Alkulaib, Y. (2013). Are CIVETS Stock Markets Predictable? Academy Of Accounting \& Financial Studies Journal, 17(3), pp. 1-12.

Appiah-Kusi, J. \& Menyah, K. (2003). Return Predictability in African Stock Markets, Review of Financial Economics. 12, pp. 247-270.

Asteriou, D. \& Hall, G.S. (2011). Applied Econometrics, $2^{\text {nd }}$ edition. United Kingdom: Palgrave MacMillan. 
Brooks, C. (2008). Introductory Econometrics for Finance, $2^{\text {nd }}$ edition. Cambridge, New York: Cambridge University Press.

Colombo, J. (2014). A Guide to South Africa's Economic Bubble and Coming Crisis. Available: http://www.forbes.com/sites/jessecolombo/2014/03/19/a-guide-to-south-africas-economicbubble-and-coming-crisis/2/ (Accessed 6 August 2014)

Fama, E.F. (1965). Random Walks in Stock Market Prices. Financial Analysts Journal, 21 (5), pp. 55-59.

Fama, E.F. (1970). Efficient Capital Markets: A Review of Theory and Empirical Work. Journal of Finance, 25(2), pp. 383-417.

Groenewald, N. \& Kang, K. (1993). The Semi-Strong Efficiency of the Australian Stock Market. Economic Record, 69(207), pp. 405.

Huang, B. (1995). Do Asian Stock Market Prices follow Random Walks? Evidence from the Variance Ratio Tests. Applied Financial Economics, 5(4), pp. 251-356.

Jefferis, K. \& Smith, G. (2005). The Changing Efficiency of African Stock Markets. South African Journal of Economics, 73(1), pp. 54-67.

Kapusuzoglu, A. (2013). Testing Weak Form Market Efficiency on the Istanbul Stock Exchange (ISE). International Journal of Business Management \& Economic Research, 4(2), pp. 700-705.

Ko, K.S. \& Lee, S.B. (1991). A Comparative Analysis of the Daily Behaviour of Stock Returns: Japan, US and Asian NIC's. Journal of Business Finance \& Accounting, 18(2), pp. 219-234.

Lim, K. (2009). Weak-Form Market Efficiency and Nonlinearity: Evidence from Middle East and African Stock Indices. Applied Economics Letters, 16(4-6), pp. 519-522.

Malkiel, B.G. (1973). A Random Walk Down Wall Street. Norton.

Mollah, A. (2007). Testing Weak Form Market Efficiency in Emerging Markets: Evidence from Botswana Stock Exchange. International Journal of Theoretical \& Applied Finance, 10, 6, pp. 1077-1094.

Morris, Q., Van Vuuren, G. \& Styger, P. (2009). Further Evidence of Long Memory in the South African Stock Market. South African Journal of Economics. 77(1), pp. 81-101

Nisar, S. \& Hanif, M. (2012). Testing Weak Form of Efficient Market Hypothesis: Empirical Evidence from South Asia. World Applied Sciences Journal, 17(4), pp. 414-427.

Nurunnabi, M. (2012). Testing Weak Form Efficiency of Emerging Economies: A Critical Review of Literature. Journal of Business Economics \& Management, 13(1), pp. 167-188.

Pearce, D, \& Roley, V. (1985). Stock Prices and Economic News. The Journal of Business, 58(1), p. 49.

Rosenberg, B. (1985). Persuasive Evidence of Market Inefficiency. Journal of Portfolio Management, 12, pp. 9-16.

Shiller, R.J. (1979). The Volatility of Long-Term Interest Rates and Expectations Models of the Term Structure. Journal of Political Economy, 87(6), pp. 1190-1219.

Shiller, R.J. (2003). From Efficient Markets Theory to Behavioural Finance. Journal of Economic Perspectives, 17(1), pp. 83-104.

Smith, G., Jefferis, K. \& Ryoo, H. (2002). African Stock Markets: Multiple Variance Ratio Tests of Random Walks. Applied Financial Economics, 12(7), pp. 475-484.

Smith, G. \& Ryoo, H. (1998). Variance Ratio Tests of the Random Walk Hypothesis for European Emerging Stock Markets. European Journal of Finance, 9, pp. 290-300. 
Sorensen, E.H. (1982). Rational Expectations and the Impact of Money upon Stock Prices. Journal of Financial \& Quantitative Analysis, 17(5), pp. 649-662.

Urrutia, J.L. (1995). Test of Random Walk and Market Efficiency for Latin American Emerging Equity Markets. Journal of Financial Research, 18, pp. 299-309.

Varamini, H. \& Kalash, S. (2008). Testing Market Efficiency for Different Market Capitalization Funds. American Journal of Business, 23(2), pp. 17-26.

Youssef, A. \& Galloppo, G. (2013). The Efficiency of Emerging Stock Market: Evidence from Asia and Africa. Global Journal of Business Research (GJBR), 7(4), pp. 1-17. 